\title{
12 | En busca del arquetipo perdido. Pabellón de invitados en Kempsey, Nueva Gales del Sur, Australia (G. Murcutt, 1992)
}

Miguel de Lózar de la Viña

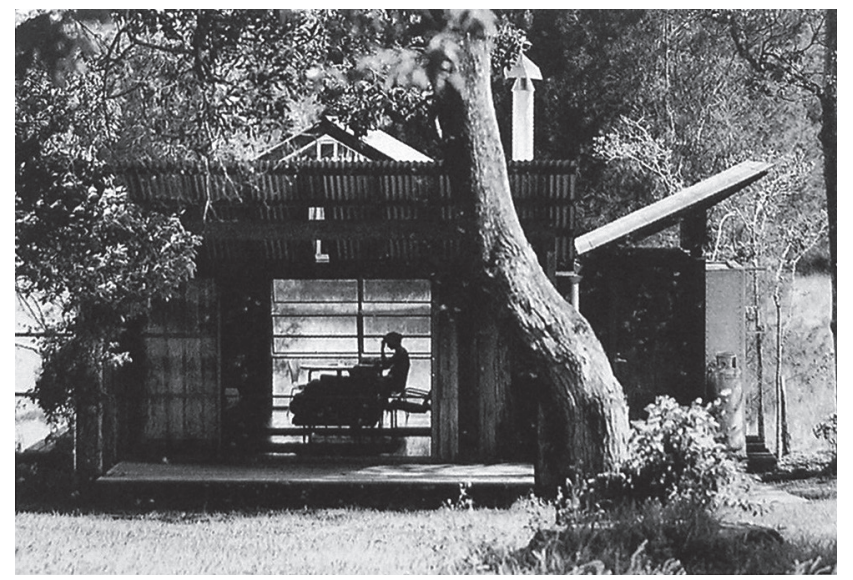

[1]

La historia de esta pequeña casa de invitados comienza mucho antes de su construcción. Veinte años antes, en 1972, Glenn Murcutt realizó el proyecto para una casa situada en un paraje natural cercano a Sidney. La propietaria de esta casa, Laurie Short, quedó satisfecha con el trabajo realizado por su arquitecto así que, dos años más tarde, cuando su madre se embarcó en la construcción de otra casa en Kempsey, una comarca situada a unos $400 \mathrm{~km}$ al norte de Sídney, Glenn Murcutt volvió a estar allí. Sin embargo, se puede decir que el arquitecto ya no era exactamente el mismo.

Durante ese intervalo de tiempo Murcutt realizó un gran viaje que le llevó por EE.UU. y Europa' Cuando regresó a Australia, lo hizo con la convicción de que su arquitectura ya no volvería a ser la misma. El profundo desengaño sufrido al descubrir la falta de interés con la que arquitectos como Mies van der Rohe (1886-1969) habían tratado el funcionamiento climático de sus edificios, así como el encuentro con otros arquitectos que, como el español José Antonio Coderch (1913-84), venían practicando otro tipo de arquitectura más vinculada con sus territorios a través de una mejor adaptación a su clima, hicieron de este viaje un punto de inflexión en la carrera de Glenn Murcutt.

En 1974, con la casa para Marie Short, Murcutt puso en práctica su nueva arquitectura con la intención de construir una auténtica máquina climática que pudiera ser regulada en todo momento por sus habitantes. Una vez construida, el que quedó realmente satisfecho con la casa fue el propio arquitecto que, pocos años después, en 1980, terminó por comprársela a su primera propietaria. Ese mismo año Murcutt acometió las obras de ampliación de la vivienda para adaptarla a las nuevas necesidades familiares, aprovechando para desmontar y guardar en algún cobertizo una pérgola de madera que su antigua clienta le había pedido que construyese pero que, sin embargo, no entusiasmaba al arquitecto [2]. Esta pérgola y el viejo cobertizo situado en los alrededores de la vivienda, serán el origen de lo que doce años más tarde se convertiría en el pequeño pabellón para invitados objeto de este estudio².

\section{El cobertizo primitivo}

En estos doce años, Murcutt, además de construir decenas de casas, se dedicó a sacar adelante la explotación agrícola que, junto con la casa, le compró a la señora Marie Short. En alguna de las fotos publicadas le vemos conduciendo un antiguo tractor [3]. Su casa, borrosa, aparece al fondo y, si uno no está bien informado, podría pensar que el tractor lo acaba de sacar de allí, de uno de aquellos woolsheds -construcciones destinadas a conservar la lana- que pueblan la geografía rural australiana. $Y$ es que, al contrario que en las villas palladianas ${ }^{3}$, en el caso de Murcutt son los atributos de una arquitectura productiva los que dominan la intervención. Con Murcutt, es la vivienda la que se vuelve invisible, confundiéndose en el paisaje como un elemen-
Resumen pág 47 | Bibliografía pág 53 Miguel de Lózar de la Viña, Madrid, 1976. Doctor Arquitecto Cum Laude por la Escuela Técnica Superior de Arquitectura de Madrid, 2014; Arquitecto, Escuela Técnica Superior de Arquitectura de Madrid, 2004; DESS Urbanisme et Gestion de Villes, Université Paris XII, 2000. Profesor invitado en la Escuela de Ingeniería y Arquitectura de Zaragoza, ha publicado artículos de investigación en revistas especializadas de ámbito internacional. Finalista del concurso internacional "The Great Egyptian Museum", Egipto 2003, es cofundador de estudio2arquitectos.

\section{Palabras clave}

Glenn Murcutt, arquitectura moderna,

cabaña, arquetipo, técnica, sentido

[1] Casa de invitados. Exterior. Vista de la fachada norte. Fotografia de Anthony Browell escaneado en FARRELLY, Elizabeth, Three Hous es: Glenn Murcutt. Londres: Phaidon, 1993.
${ }^{1}$ Murcutt fue galardonado con el Gray-Mulroney Award en 1972 por la ampliación de su casa en Mosman (Sidney), un proyecto que realizó entre los años 1968 y 1969 . Murcutt reconfiguraba una antigua vivienda de la periferia mediante una actuación que mantenía su fachada exterior y que se centraba en la relación entre la vivienda y su jardín trasero. El premio era una beca para dar una vuelta al mundo. Durante tres meses, en 1973, recorrió América, desde México a Canadá, y Europa, desde España hasta Grecia, con hitos como su encuentro con Craig Ellwood-admirado por Murcutt en su condición de continuador de la obra de Mies- en su casa de Los Ángeles (casa Kubly, 1964-65), su visita en París a la Maison de Verre (1928-1931), de Pierre Chareau y Bernard Bijvoët, donde el arquitec to australiano apreció el equilibrio mantenido entre la industria moderna y la más refinada artesanía, y su encuentro con la arquitectura de raíces mediterráneas de José Antonio Coderch en su casa de Cadaqués (1958). 
2 Fromonot nos cuenta en su libro como Murcutt recuperó para su pabellón de invitados la vieja pérgola de la casa Marie Short para reestructurar un antiguo cobertizo agrícola: "II legno del pergolato [de la casa Marie Short] é servito per ristrutturare un cappanone deIl'azienda agricola trasformandolo in camera per gli ospiti". FROMONOT, Françoise. Glen Murcutt. $2^{a}$ ed. Milán: Electa, 2003, p. 96.

${ }^{3}$ En las villas del seiscientos italiano, realizadas por Andrea Palladio (1508-1580), el arquitecto se preocupaba por dotar al conjunto, tanto a las pars urbana, como a la pars rustica, de un estilo unificado en el que la parte representativa parecía abarcar todo e complejo de la villa, incluidos sus elementos puramente productivos.

${ }^{4}$ El origen de la influencia del pensamiento de H D. Thoreau (Concord, Massachusetts, EE.UU., 1817-1862) en Glenn Murcutt se haya en su padre, Arthur Murcutt, para quien el filósofo trascendentalista fue su principal referencia moral. Arthur, promotor y constructor de viviendas, supo trasmitir a su hijo, aún antes de que Glenn entrara en la Escuela de Arquitectura de Sidney, una comprensión de la arquitectura a través del pensamiento de Thoreau. En su viaje de 1973 a los EE.UU., Glenn Murcutt realizó la peregrinación hasta Concord para visitar la cabaña en la que el filósofo vivió desde 1845 hasta 1847 y cuya experiencia de vida en los bosques daria lugar a la publicación de Walden en 1854.

${ }^{\mathbf{5}}$ Este texto es la traducción que el autor ha realizado del texto en italiano que a continuación se reproduce: "Murcutt invidia el carattere profondamente ontologico e simbolico delle capanne aborigene, fatte di corteccia e di rami, che partecipano del loro contesto immediato e richiedono un'elaborazione architettonica minima". FROMONOT, Françoise. Glenn Murcutt. $2^{\mathrm{a}}$ ed. Milán: Electa,

6 "Glenn ricorda que il padre gli aveva im posto, quando aveva appena quindici anni, di leggere un articolo sulla casa Farnsworth di Mies van der Rohe". FROMONOT, Françoise. Glenn Murcutt. $2^{\mathrm{a}}$ ed. Milán: Electa, 2003, p. 20. 2003 , p. 39

to más del utillaje agrícola. De este modo, el hecho de elegir un antiguo cobertizo para adecuarlo como casa de invitados resultaba en extremo lógico.

En la construcción de su nueva cabaña, Murcutt -al igual que hiciese Thoreau (1817-1862) con su cabaña en Walden- trabajará con sus propias manos uniendo acción y reflexión $n^{4}$. Así, mientras el filósofo americano recorrió apenas dos kilómetros desde su natal Concord hasta la laguna junto a la que decidió instalarse, estableciendo entre su nueva morada y el pueblo una distancia más espiritual que física, los 80 metros que recorre Murcutt para emplazar su cabaña se pueden leer como un eco de aquel pequeño viaje en busca de retiro ${ }^{4}$ [4].

El cobertizo será sometido a una serie de operaciones de precisión quirúrgica. Se repararán los elementos deteriorados, se eliminarán aquellas partes inservibles y se equipará con las prótesis necesarias que le permitan hacer frente a las nuevas necesidades: nuevos pies para levantarlo del suelo; nuevos accesos para alcanzar ésta cota más elevada; nuevos ojos para poder relacionarse mejor con su contexto; prótesis protectoras para estos ojos; un nuevo órgano dedicado a la higiene del cuerpo con capacidad, asimismo, para acumular reservas energéticas; mecanismos de regulación climática, de recogida de agua de lluvia y de protección frente a esta; así como una pequeña rasgadura a través de la cual se pueda entrever el cielo. En definitiva, todo aquello que, según Murcutt, hace falta para que un cobertizo pueda ser llamado, también, una casa [5].

Cabe destacar esta tensión entre la construcción del cobertizo y la vivienda que el arquitecto pretende alcanzar. En este sentido, cuando Murcutt nos dice que "envidia el carácter profundamente ontológico y simbólico de la cabaña aborigen"5, nos está dando otra clave para comprender su interés en la conservación del cobertizo, que asumiría ahora este carácter simbólico y elemental de la cabaña aborigen. Sin embargo, la intervención de Murcutt no se limita a una puesta en valor de esta sencilla construcción, sino que pretende trascenderla y, para ello, la hibridará con aquella tipología que había venido utilizando en sus viviendas a lo largo de toda su carrera, la del pabellón de vidrio.

\section{Una identidad tipológica}

Desde el momento en que Murcutt descubrió, a través de su padre, la casa Farnsworth (194550), de Mies van der Rohe [6], se formó en su interior el molde con el que, indefectiblemente, habría de construir cada una de sus obras: el pabellón de vidrio ${ }^{6}$. Efectivamente, su padre -aventurero, buscador de oro y, finalmente, constructor de viviendas- encontró en la casa Farnsworth aquello que Thoreau, su principal referencia filosófica y moral, escribiera un siglo antes acerca de la casa de sus sueños: una casa construida "sin adornos superfluos, que consista en una sola habitación, una sala enorme, con vigas y juntas al aire que soporten una especie de firmamento interior sobre nuestra cabeza (...")"

Durante toda su carrera, Murcutt se mantendrá fiel a esta tipología. Así, en función del programa requerido, el arquitecto se planteará básicamente dos opciones, alojarlo todo en un único

[2]

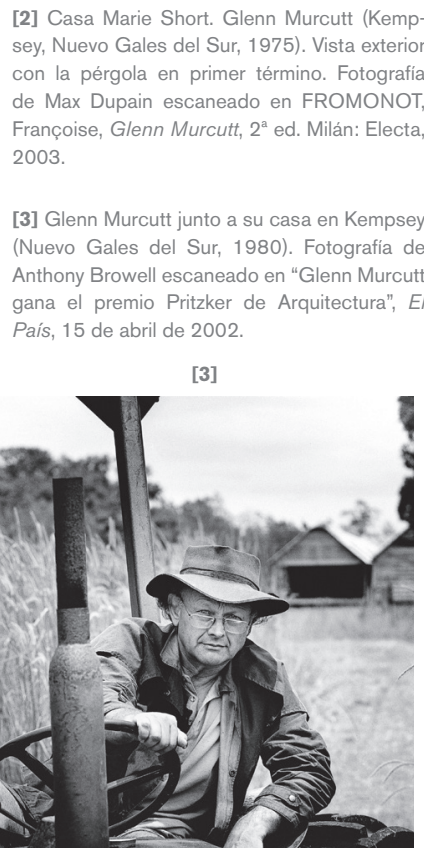

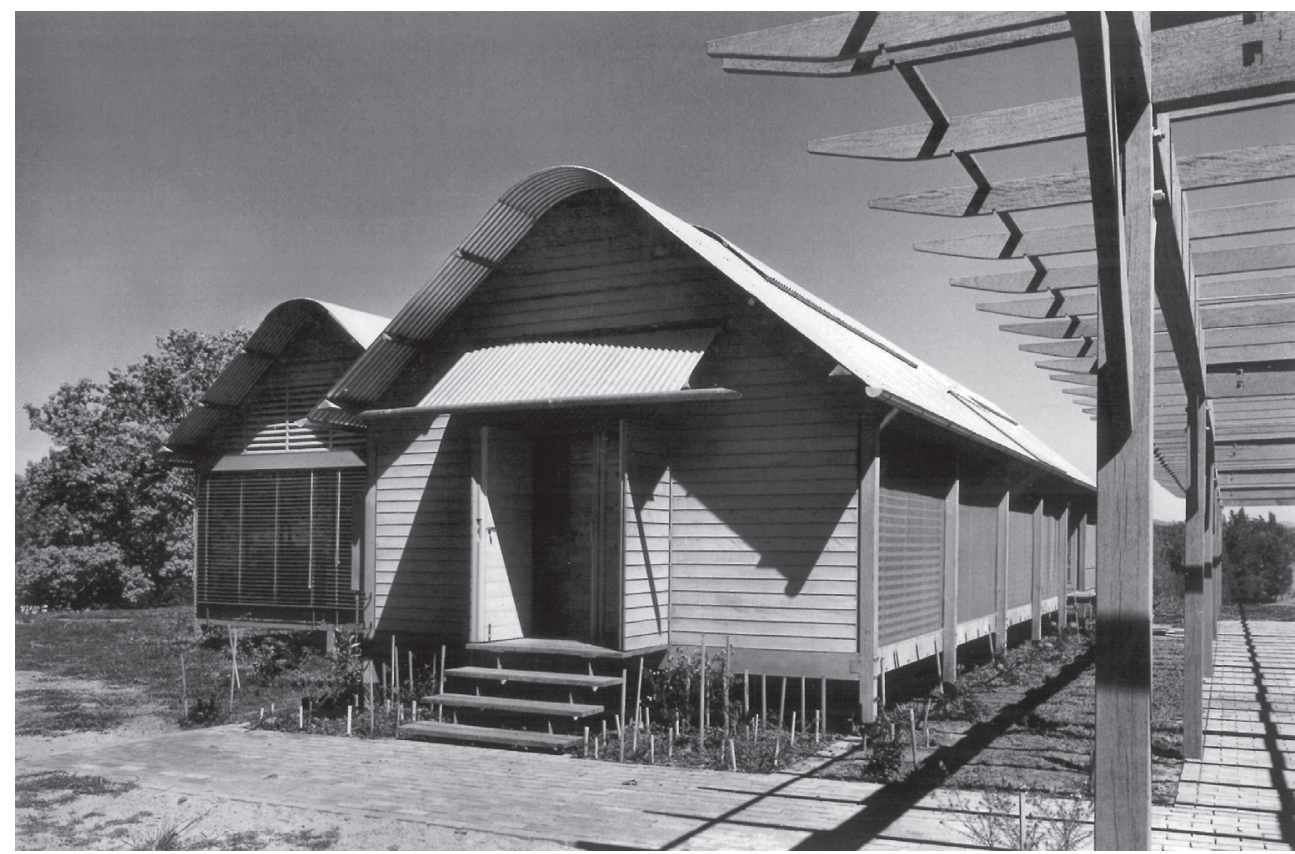




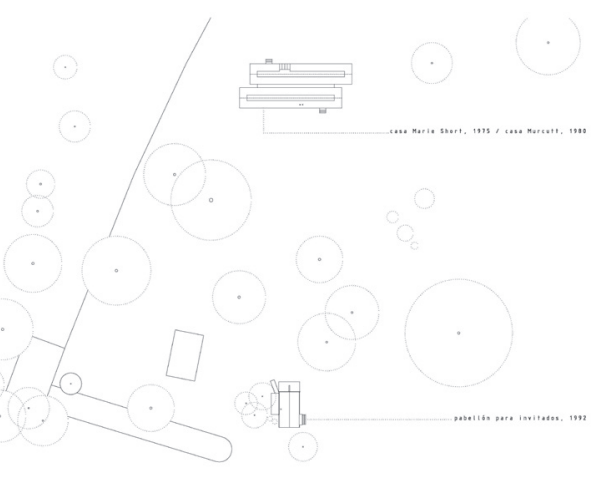

[4]

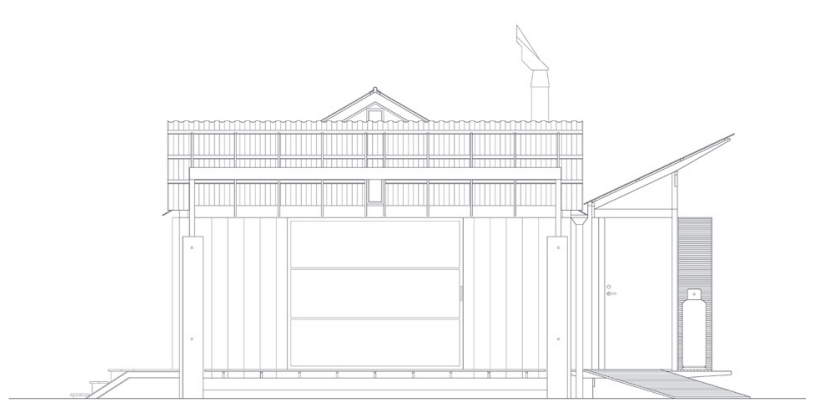

[5]

pabellón, potenciando así su linealidad, como en el caso de la casa Ball-Eastway (1980-83) o, al contrario, segregar el programa en distintos pabellones paralelos al eje principal, como sucede en la misma casa Marie Short. Esta continua prueba a la que Murcutt somete la tipología del pabellón de vidrio, adaptándola siempre a distintos contextos, nos habla de una identificación con el arquetipo de la casa y, por extensión, de la arquitectura, pues es en esta repetibilidad como "instrumento tipo", tal y como ha escrito Rafael Moneo, donde reside la esencia de la casa primitiva: "construir una cabaña pasaba por solucionar problemas de forma y diseño similares (...) al trenzado de una cesta (...) que van de la construcción al uso y que permiten su reproducción (...) su repetibilidad"8.

\section{En busca del arquetipo}

Murcutt, en el pabellón de invitados de Kempsey, realizará una síntesis entre el cobertizo primitivo sobre el que actúa y la tipología del pabellón de vidrio que trae consigo. De esta unión, que podría definirse como mágica, surgirá una arquitectura que aunará el carácter simbólico del cobertizo y el ontológico del pabellón de vidrio: un arquetipo. Así, en su actuación sobre el primitivo cobertizo, Murcutt toma la decisión de explicitar el carácter independiente de la estructura con respecto al cerramiento, estableciendo una relación directa con el origen ilustrado de la tipología del pabellón de vidrio: la reconstrucción de la cabaña primitiva con la que Marc-Antoine Laugier (1713-1769) abría su Essai sur l'architecture ${ }^{9}$, y en la que el abate realizaba una crítica de la que consideraba retórica y decadente arquitectura barroca, buscando depurarla a través de criterios técnicos, identificando arquitectura con estructura [7].

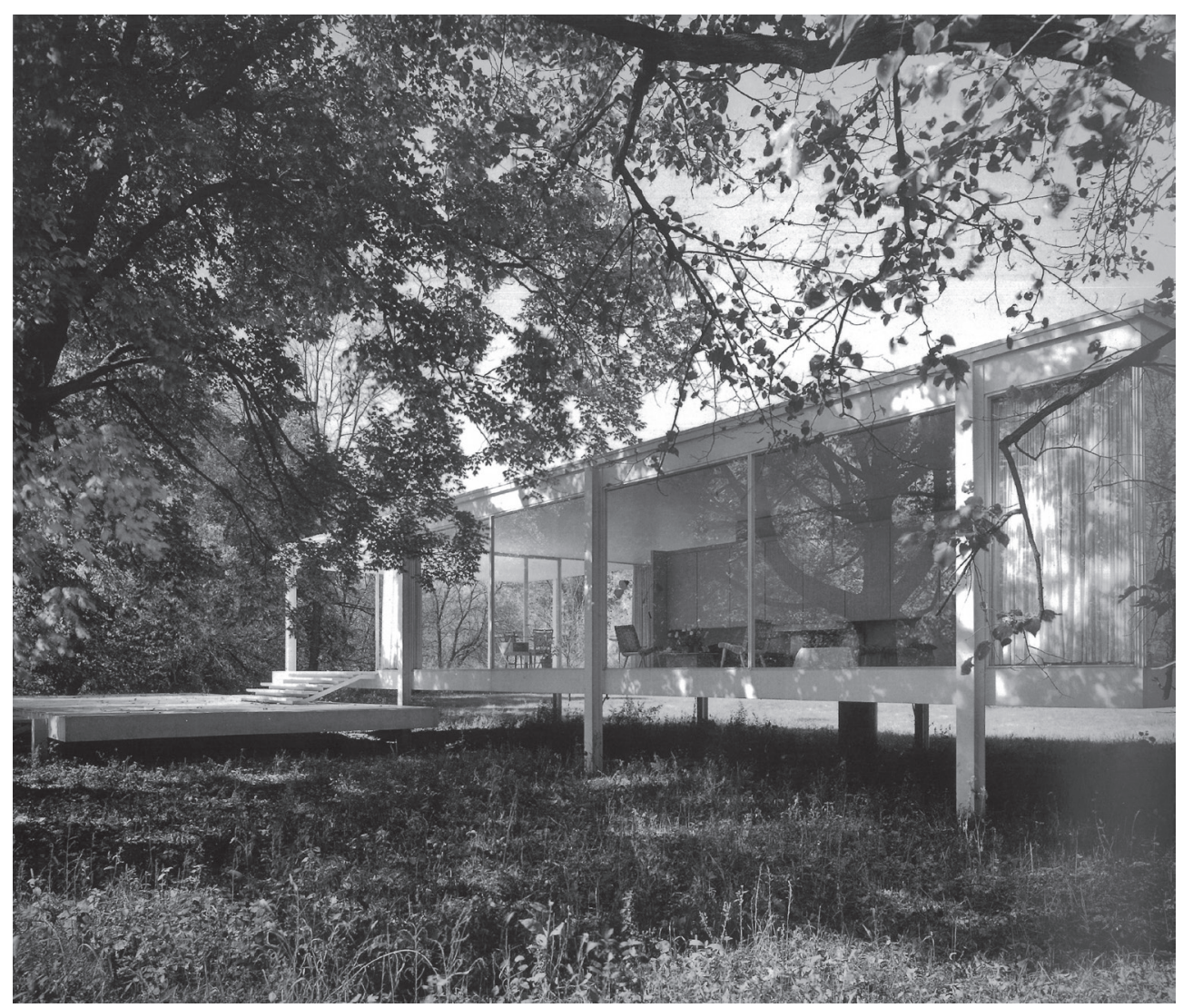

7 THOREAU, Henry David. Walden. Madrid: Ediciones Cátedra, 2005, p. 133.

${ }^{8}$ MONEO, Rafael. "Sobre la noción de tipo". El croquis. Rafael Moneo, 1967-2004. 2004 ( $\left.{ }^{\circ} 20+64+98\right)$, p. 586.

9 EI Essai sur l'architecture lo publicó Laugier por primera vez en Paris, en 1753, de manera anónima. No sería hasta dos años después, en 1755 , cuando aparecería una segunda edifición firmada por su autor.

${ }^{10}$ Thoreau ponía como ejemplo de cobijo ligero las tiendas de los indios norteamericanos, capaces de resistir los más crudos inviernos. THOREAU, Henry David. Walden. Madrid: Ediciones Cátedra, 2005, p. 93. 
[4] Casa de invitados. Levantamiento planimétrico. Situación. Dibujo del autor.

[5] Casa de invitados. Levantamiento planimétrico. Alzado norte. Dibujo del autor.

[6] Casa Farnsworth. Mies van der Rohe (1945-50). Fotografía de Hedrich Blessing escaneado en CARTER, Peter, Mies van der Rohe at work. Londres: Phaidon, 1999.

[7] Frontispicio escaneado en LAUGIER, Marc-Antoine, Essai sur l'architecture, Genève: Minkoff Reprint, 1972.

[8] Casa de invitados. Levantamiento planimétrico. Planta. Dibujo del autor.

[9] Casa de invitados. Levantamiento planimétrico. Sección transversal. Dibujo del autor.

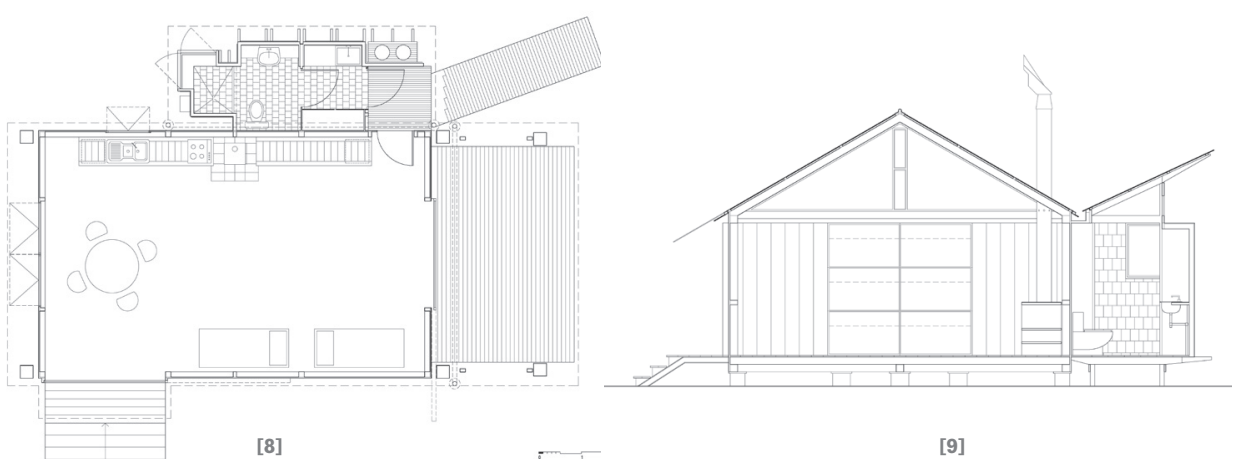

La transformación del cobertizo en pabellón prosigue reforzando su linealidad al ampliar el eje longitudinal del pabellón de invitados, a través del vidrio, hacia el paisaje. Este eje norte-sur se refuerza, asimismo, con la adición de la veranda en la fachada norte que, gracias a la disposición de su cubierta, funciona como un altavoz que amplifica la relación del pabellón con el paisaje. Tanto la disposición de la veranda, a continuación del espacio cerrado de la vivienda, como la disposición paralela al eje longitudinal del pequeño núcleo de servicios [8], inciden en la axialidad de la construcción, en un proceso que sigue las mismas reglas utilizadas por Mies en la disposición tanto del porche como del podio de acceso a la casa Farnsworth.

Gracias a esta fuerte longitudinalidad, el pabellón consigue, a pesar de sus reducidas dimensiones, emanar un gran dinamismo que, junto con la sensación de ligereza y transitoriedad que se desprende de su posición sobreelevada, nos informan de otro elemento en común con el pensamiento de Thoreau: la tienda como referente de una arquitectura ligera. Si tectónicamente el arquetipo de este pabellón lo encontramos en la cabaña, es, sin embargo, el arquetipo de la tienda el que expresa su voluntad de relacionarse con el mundo con la libertad del nómada ${ }^{10}$. Murcutt, por tanto, no hace aquí sino continuar una corriente arquitectónica que tiene sus raíces en el trascendentalismo americano del siglo XIX, y que ya había encontrado en Frank Lloyd Wright (1867-1959) a su primer gran adalid, con construcciones como el campamento de Ocatillo (1929) o Taliesin West (1937), buena muestra de lo que este gran nómada entendió por una arquitectura ligera $y$, por eso mismo, libre ${ }^{11}$. A diferencia de estos ejemplos wrightianos -auténticos veleros del desierto gracias a sus cubiertas de lona blanca-, las velas que Murcutt desplie-

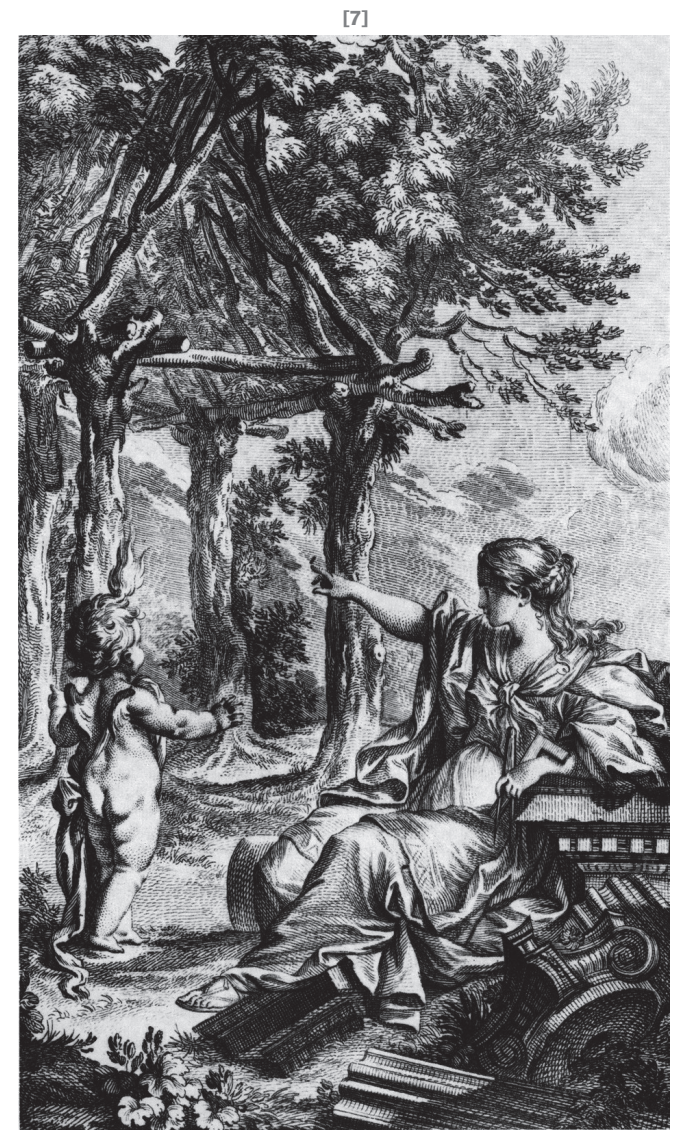




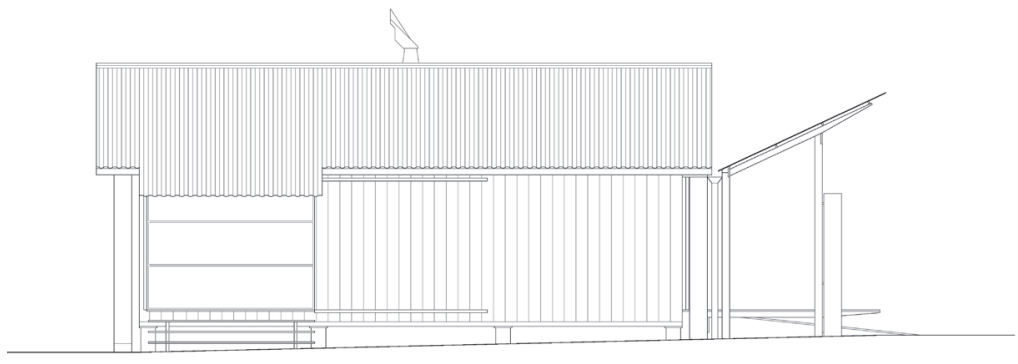

[10]

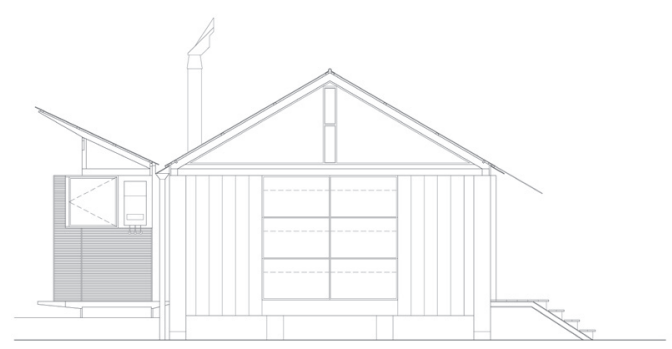

[12]

ga en su navío no son de tela, sino metálicas. El arquitecto australiano dota, sin embargo, a la cubierta de este pabellón de la misma ligereza que poseían sus precedentes americanos en un ejercicio de desmaterialización en el que, capa tras capa, se van eliminando los materiales que la componen, afinando al límite su espesor hasta dejarlas, finalmente, reducidas a los escasos milímetros de la chapa de zincalume ${ }^{12}$. [9]

\section{El pabellón de invitados como nexo entre la naturaleza, el cosmos y el hombre}

Como le sucede a cualquier viajero, esta arquitectura de espíritu nómada necesita orientarse, situarse en relación con el sol o las estrellas, para no perder su camino. Esta puede ser la razón por la que en muchas de las casas de Murcutt nos encontramos con una ventana que se abre en la cubierta y que mira directamente al cielo. Sin embargo, en el pabellón para invitados esta ventana ha desaparecido. En un espacio de tan reducidas dimensiones puede que el arquitecto no la considerara necesaria. Aun así, Murcutt, para no dejar la casa completamente a la deriva, no ha podido evitar dotarla de una brújula. Mediante una pequeña apertura, que actúa como gnomon, dispuesta en la cubierta de la veranda norte, un rayo de sol entra en la vivienda marcando el paso del tiempo a medida que se desplaza, situando la casa en permanente relación con el cosmos.

De esta forma la casa pasa a ocupar un espacio situado en un punto intermedio entre el universo y la naturaleza que la rodea, constituyéndose, para el hombre que la habita, en el nexo de unión entre estas dos esferas. Por otro lado, las múltiples aperturas de la vivienda hacia el paisaje buscan establecer una relación más estrecha con su entorno. Esta voluntad de conexión con la naturaleza es, sin embargo, limitada, ya que Murcutt no llega a permitir que los dos ámbitos, el de la naturaleza y el del hombre, terminen por mezclarse. Inmersa en el poderoso paisaje australiano, la casa ha de poder crear un microcosmos independiente como refugio de sus habitantes. Para lograr este objetivo, Murcutt ejerce un claro control sobre aquellos puntos de mayor contacto entre la vivienda y la naturaleza que la rodea, estableciendo transiciones entre estos dos ámbitos que aseguren la necesaria autonomía de cada uno de ellos.

Una de las primeras medidas que se toman es elevar la vivienda del suelo, permitiendo a la naturaleza fluir bajo ella al tiempo que, psicológicamente, se separa al hombre de su entorno [10]. Los accesos se entienden, de este modo, como espacios de transición definidos por pequeños umbráculos que, en la veranda, pasan a convertirse en una verdadera habitación al aire libre. Esta relación dialéctica que establece el pabellón con su contexto y que orbita entre la apertura hacia el paisaje y su alejamiento de él, encuentra, en el juego de contrastes con que se materializa su construcción, su expresión formal. El uso de materiales más naturales como la madera, colocada junto con la chapa corrugada de las cubiertas o el aluminio de las carpinterías, nos habla de esta tensión entre lo natural y lo artificial. Este juego de contrastes tiene, asimismo, una lectura que nos habla de otra relación conflictiva que se supera desde la aceptación de la autonomía de dos mundos bien diferenciados: el pasado y su integración en el presente o, casi podríamos decirlo al contrario, el presente y su integración en el pasado.

Murcutt, con una percepción postmoderna que se puede rastrear ya en la generación de arquitectos a la que pertenecen el italiano Carlo Scarpa (1906-1978) o el español José Antonio Coderch $^{13}$, juega con el tiempo yendo al pasado y regresando al futuro en un bucle que se cierra sobre sí mismo y que encierra, como en un juego de muñecas rusas, nuevos contrastes. Colocando las viejas tablas del cobertizo junto a las delicadas carpinterías de aluminio, se exponen los más básicos rudimentos de la construcción acompañados de una tecnología que, aún hoy, solo se encuentra al alcance de unos pocos. Por otro lado, la exposición al desnudo de las instalaciones -como las bombonas de combustible- así como el uso de los materiales en su estado natural, lo conectan con la arquitectura brutalista británica de posguerra, representada en Alison (1928-1993) y Peter (1923-2003) Smithson ${ }^{14}$ [11].
11 El campamento de Ocatillo surgió ante la necesidad de alojamiento para Wright y su grupo de aprendices cuando se trasladaron a comienzos de 1929, y durante cinco meses, al desierto de Arizona para proyectar in situ el complejo turístico San Marcos in the Desert. En Ocatillo Wright construyó su particular cabaña o, más bien, tienda primitiva, haciendo de las ligeras cubiertas de lona blanca de las cabañas el leitmotiv de la intervención. En Taliesin West, construido en 1937, Wright buscaba reencontrarse con ese espiritu de ligereza y libertad que animó el campamento de Ocatillo, y es por ello que, durante los primeros años, cada invierno, al llegar a Taliesin West, la tribu de nómadas pastoreada por Wright colocaba las cubiertas de lona blanca en el salón del edificio, retirándolas al finalizar la temporada. Cfr. LÓZAR, Miguel de, "Ocatillo, the Sailboat of the Desert", Frank Lloyd Wright Quarterly, 2014 , vol. $25, n^{\circ} 3$, p. $24-45$

12 Murcutt se inspirará en la Angophora costata, cuyas hojas afiladas, para no ser consumidas por el sol australiano, le dan su característico perfil vibrante. Es su referencia a la hora de conjugar, en lo que él ha denominado feathering, esta desmaterialización y afinamiento con el que sus edificios buscan relacionarse con el entorno.

13 Según Françoise Fromonot, la casa de invitados de Murcutt, en palabras del propio arquitecto, es un ejercicio "alla Scarpa". FROMONOT, Françoise. Glenn Murcutt. $2^{\mathrm{a}}$ ed. Milano: Electa, 2003, p. 228. Sin embargo, cabe señalar otro referente para Murcutt a la hora de acometer este ejercicio arquitectónico en la figura de José Antonio Coderch, al que Glenn Murcutt visitó en su rehabilitada casa de Cadaqués en 1973 y que, según Philip Drew "showed how it was possible to respect the past without demeaning the present". DREW, Philip. Leaves of Iron. Glenn Murcutt: Pioneer of an Australian Architectural Form. Sidney: The Law Book Company Limited, 1985, p. 42.

14 Esta conexión entre Glenn Murcutt y Alison y Peter Smithson se puede comprobar comparando el pabellón de invitados del australiano con el pabellón solar (1958 - 1982) que los británicos se construyeron como casa de recreo en Upper Lawn. Aquí los Smithson realizaron un ejercicio similar al de Murcutt, jugando con las preexistencias de una antigua casa arruinada o buscando el contraste entre materiales naturales, como la madera, e industriales, como el aluminio, en un experimento que, gracias al extensivo uso del vidrio, se planteaba también como una casa climática. En este último aspecto, el pabellón, al carecer de protección solar, nunca funcionó bien pues, tal y como reconocian los propios arquitectos, incluso en la poco soleada Inglaterra, la casa se hacía invivible en los meses de verano. 
[10] - Casa de invitados. Levantamiento planimétrico. Alzado este. Dibujo del autor.

[11] Casa de invitados. Levantamiento planimétrico. Alzado oeste. Dibujo del autor

[12] Casa de invitados. Levantamiento planimétrico. Alzado sur. Dibujo del autor.

[13] Casa de invitados. Levantamiento planimétrico. Sección longitudinal. Dibujo del autor.
Esta dialéctica de la técnica corre en paralelo al diálogo que se establece entre los elementos de una cultura popular, tradicional y rural, frente a los que han sido extraídos de una cultura necesariamente urbana. A través del tratamiento del cobertizo como objet trouvé se expresa la individualidad de aquel que ha sabido encontrarlo y resituarlo correctamente en su nuevo contexto, frente a la mentalidad colectiva que se situaba detrás de una arquitectura determinada por los usos y costumbres. La consideración del cobertizo como un objet trouvé se acentúa por el diferente tratamiento que se da a las piezas que se le agregan: el pabellón de servicio y la veranda. En ambas, la disposición de sus cubiertas, en confrontación con la del pabellón principal, refuerza su independencia, mientras que el recubrimiento del pabellón de servicio con chapa corrugada, frente al revestimiento de madera del pabellón principal, refuerza el contraste y facilita la lectura entre lo antiguo y lo nuevo [12].

\section{Un uso racional de los recursos}

Finalmente, dentro de este aparentemente infinito juego de espejos, se podría establecer una última relación dialéctica entre lo nuevo, es decir, aquello que ha sido concebido y fabricado expresamente para su colocación en esta obra, y lo reciclado, aquellos materiales que habiendo perdido su uso primitivo son reutilizados en esta construcción. Es este valor concedido al reciclaje en sí mismo lo que diferencia la intervención de Murcutt frente a las de arquitectos como Scarpa o Coderch. En la casa de pescadores que Coderch rehabilita en Cadaqués (1958), el debate se centra entre lo antiguo y lo nuevo, con las diferentes técnicas y estilos asociados a cada uno de estos momentos dialogando entre sí. En el caso del pabellón de invitados de Murcutt, además de producirse esta conversación entre lo antiguo y lo nuevo, se introducen elementos que, aun siendo existentes, son transformados mediante su cambio de uso.

Se podrían distinguir, entonces, los elementos restaurados -aquellos pertenecientes al viejo cobertizo y que, una vez saneados, fueron reutilizados sin que se alterase su función- de aquellos otros elementos que cambiaron totalmente de uso, como la antigua pérgola que, tras adornar el jardín de la señora Marie Short, pasa a convertirse ahora en parte de la estructura del pabellón. El origen de esta nueva dialéctica no es formal, sino que se encuadra en la utilización racional de unos recursos limitados. Algo que, según Murcutt, pasa necesariamente por el reciclaje y por el uso de materiales que, aunque nuevos, puedan ser reciclados. Este uso racional de los recursos se encuadra en una estrategia proyectual más amplia que busca establecer, gracias al acondicionamiento climático pasivo de la vivienda, una relación con el entorno que haga del respeto su principal argumento.

La veranda del pabellón de invitados es un bello ejemplo de este método de trabajo del arquitecto. Situada en la fachada norte, su principal función es proteger con su ligera cubierta a la vivienda del excesivo soleamiento de los meses de verano. Sin embargo, el mayor interés del arquitecto no era tanto éste como el de que la propia veranda no se constituyese en un obstáculo para que la vivienda pudiese recibir el igualmente necesario sol de invierno. Para solucionar el problema, Murcutt coloca la cubierta de la veranda exactamente al revés que en el típico porche, es decir, con su pendiente conduciendo las aguas hacia la propia vivienda. Esta disposición invertida resulta de su configuración en función de la posición del sol en el solsticio de invierno, con una dirección y una pendiente que permiten que éste entre hasta el interior del pabellón. Como el testero de la casa es acristalado, el sol consigue penetrar en la vivienda por toda su fachada norte, tanto por encima como por debajo de la cubierta de la veranda. La protección frente al sol del verano, mucho más vertical, se consigue dimensionando correctamente la profundidad de la veranda y del pequeño vuelo que tiene la cubierta del pabellón principal. Esta disposición invertida de la cubierta tiene la ventaja añadida de que el interior de la vivienda disfruta siempre de una buena iluminación natural, ya que, en los meses de verano, cuando la veranda está en sombra, la luz entra a la vivienda por la parte superior del cerramiento de vidrio después de rebotar en la cara superior de la cubierta de la veranda, convirtiendo así al techo de la habitación en una lámpara que distribuye toda la luz que recibe de la cubierta metálica [13].
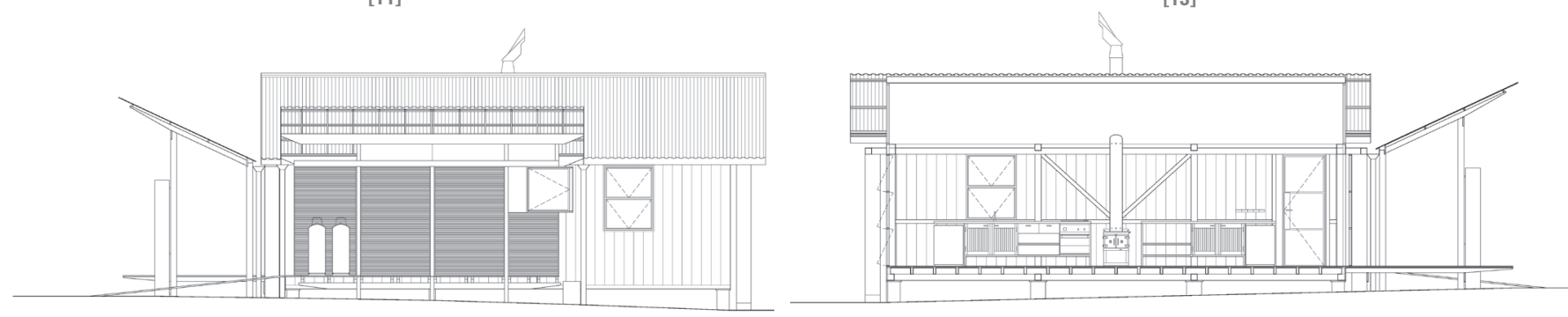


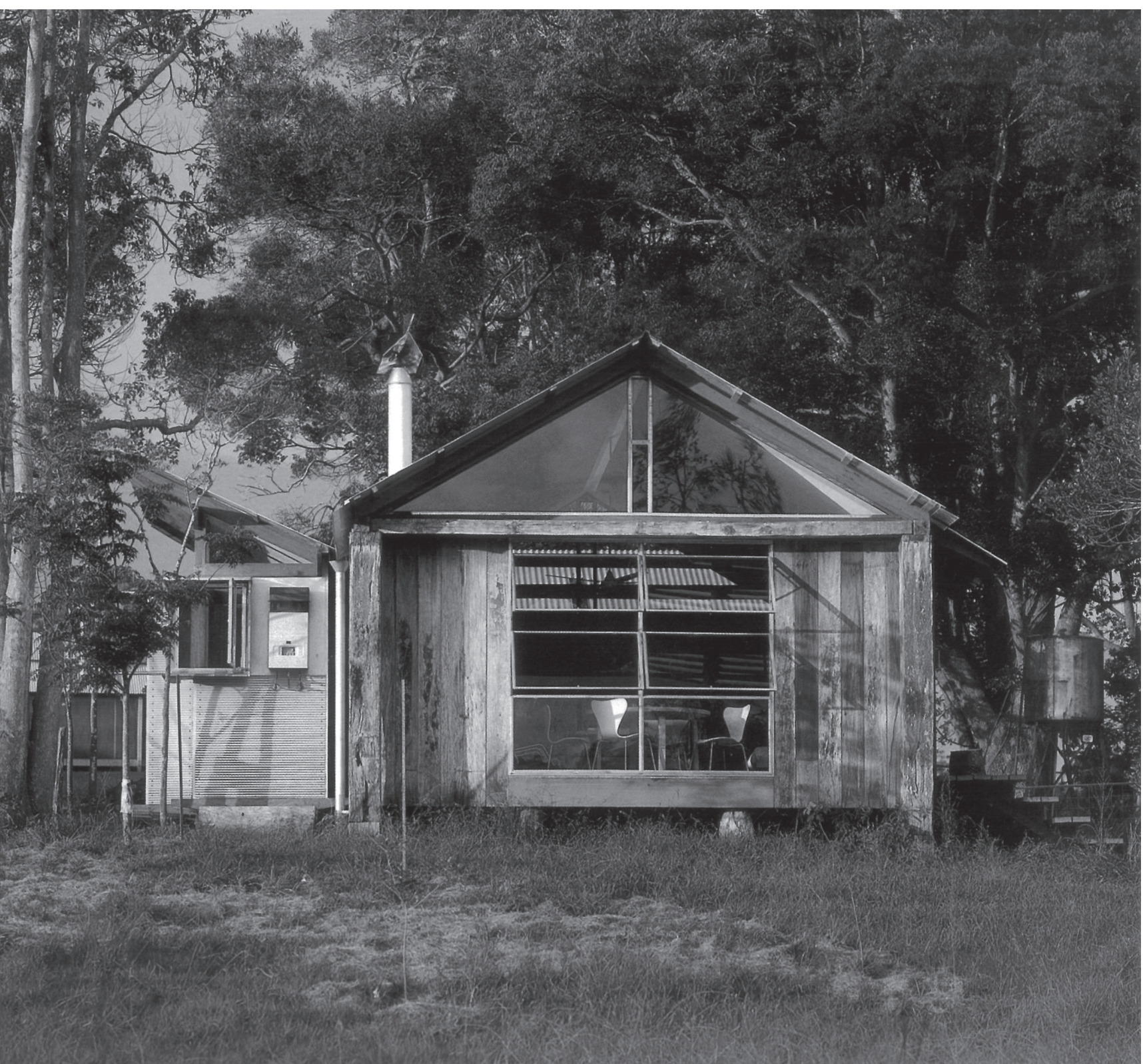

El cuidado con el que Murcutt estudia el correcto soleamiento de esta casa se ve igualmente reflejado en la atención que le dedica a la ventilación. Para permitir que el aire pueda circular y refrescar el interior del pabellón, se sirve de un sencillo esquema de ventilación cruzada que, sin embargo, refina mediante una serie de dispositivos, como las lamas de aireación instaladas en el ventanal de la fachada sur o los pequeños aireadores ubicados en los grandes ventanales triangulares que cierran los piñones de la cubierta [14]. Estos últimos son realmente importantes, ya que aseguran la evacuación del aire caliente que de otra manera se acumularía en las capas más altas del interior del pabellón. Finalmente, al levantar la casa sobre pequeños pilotis, además de evitar el contacto directo con la humedad del terreno, Murcutt consigue que una permanente corriente de aire circule por debajo de la construcción, secando las posibles humedades y refrescando el suelo de la vivienda. Junto a estos mecanismos, estrictamente pasivos, destaca la presencia en el centro de la sala de un ventilador de techo. Este aparato eléctrico, uno de los más rudimentarios y eficaces mecanismos de climatización, se convierte, junto con las chimeneas de leña, en un símbolo de la arquitectura de Glenn Murcutt, indicándonos el máximo gasto energético que el arquitecto está dispuesto a asumir en la climatización de una vivienda.

\section{Conclusiones}

Desde San Agustín, que señaló la muerte de Jesús en la cruz como el punto de inflexión que convertía el tiempo en una línea que camina hacia la meta de la Redención, el tiempo lineal, sagrado -en el que podemos reconocer a tantos arquitectos fascinados por la idea de progreso- se ha contrapuesto al tiempo cíclico profano en el que los paganos, como señalaba Jan Assman ${ }^{15}$, yerran, eternamente, en círculo. Frente a la cronología sagrada, el recurrente
${ }^{15}$ Assman, egiptólogo alemán (1938). ASSMANN, Jan. Egipto. Historia de un sentido. Madrid: Abada Editores, 2005, p. 24.

${ }^{16}$ ELIADE, Mircea. Mito y realidad. $5^{\mathrm{a}}$ ed. Barcelona: Editorial Labor, 1983 p. 149 
ritmo de los días y los años, de los amaneceres y los atardeceres, es el que crea el cronotopo cíclico en el que Glenn Murcutt desarrolla su arquitectura. Cada proyecto es, para el arquitecto australiano, un nuevo comienzo en el que habrá de reencontrarse con el modelo, nunca creado, del arquetipo. Se construye así una arquitectura a punto siempre de reencontrarse a sí misma. El juego constante de Murcutt en el que, una y otra vez, repite la misma búsqueda en torno a la esencia de la arquitectura, en el que, una y otra vez, vuelve a reconstruir el arquetipo, no se reduce, sin embargo, a una mera repetición vacía de creatividad o de riesgo. El arquetipo, como elemento, en este caso, mítico, es lo que permite a Murcutt embarcarse en la difícil empresa de descubrir nuevos caminos, de adentrarse en territorios aún desconocidos, pues "el mito garantiza al hombre que lo que se dispone a hacer ha sido ya hecho, le ayuda a borrar las dudas que pudiera concebir sobre el resultado de su empresa. ¿Por qué vacilar ante una expedición marítima, puesto que el héroe mítico la efectuó en un tiempo fabuloso? No hay sino que seguir su ejemplo"16.

Se puede decir, desde esta perspectiva, que el camino transitado por Glenn Murcutt hacia una arquitectura ligera y sumamente técnica, basada en la eficiencia ambiental y en el respeto por el territorio, no habría sido posible sin una previa identificación de carácter mítico entre el arquitecto y su arquetipo. En este sentido, la casa para invitados en Kempsey (1992) supone el ejercicio más decidido por dar caza al mito, siempre escurridizo, del arquetipo de la vivienda. Aquí Murcutt parece encontrar el sitio exacto en el que la serpiente se muerde la cola, cerrando, así, el círculo en el que se encuentran, abriéndose y cerrándose simultáneamente, distintos espacios, distintos tiempos. Murcutt fabrica un crisol en el que entran en ebullición el pabellón miesiano y su primitivo y culto precursor laugeriano, junto con la arquitectura tradicional más sencilla y popular del cobertizo, en el intento por alcanzar la síntesis que trascienda a todas ellas.

Resulta claro, así, que el impulso original en la arquitectura de Glenn Murcutt no se puede buscar fuera de ella, en la naturaleza, sino que se trata de un impulso interior que surge del diálogo entre el hombre y el hecho arquitectónico y, con más intensidad aún, de una dialéctica metaarquitectónica, en la que la arquitectura adquiere valor por sí misma. Con la naturaleza, por tanto, Murcutt no podrá establecer una relación íntima, no podrá fundirse ni confundirse con ella, sino que se mantendrá separado en un espacio con sus propias reglas, totalmente independiente. Sin embargo, aun perteneciendo arquitectura y naturaleza a esferas distintas, Murcutt, como si fuera un instrumento, afinará este pequeño pabellón con su emplazamiento, para que, al compartir la misma frecuencia que su entorno, entre en armonía con él, evitando, así, los ruidos y cacofonías que, de otro modo, podrían surgir y que acabarían distorsionando la relación entre el hombre, la arquitectura y la naturaleza [15].

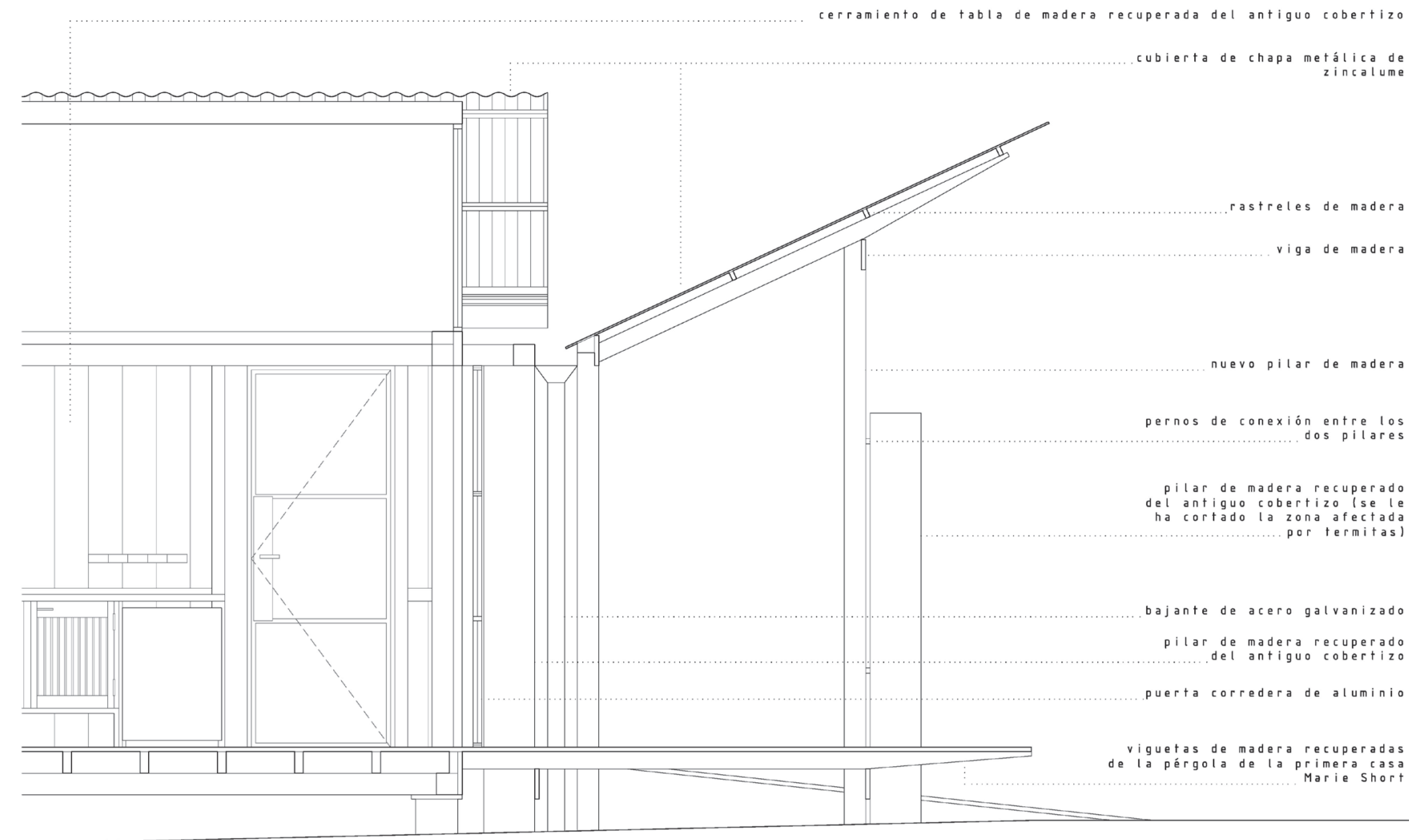

